\title{
Silver-Mediated Fluorination of Functionalized Aryl Stannanes
}

\section{Citation}

Furuya, Takeru, Alexandra E. Strom, and Tobias Ritter. 2009. Silver-mediated fluorination of functionalized aryl stannanes. Journal of the American Chemical Society 131(5): 1662-1663.

\section{Published Version}

doi:10.1021/ja8086664

\section{Permanent link}

http://nrs.harvard.edu/urn-3:HUL.InstRepos:8156524

\section{Terms of Use}

This article was downloaded from Harvard University's DASH repository, and is made available under the terms and conditions applicable to Open Access Policy Articles, as set forth at http:// nrs.harvard.edu/urn-3:HUL.InstRepos:dash.current.terms-of-use\#OAP

\section{Share Your Story}

The Harvard community has made this article openly available.

Please share how this access benefits you. Submit a story.

Accessibility 


\title{
Silver-Mediated Fluorination of Functionalized Aryl Stannanes
}

\author{
Takeru Furuya, Alexandra E. Strom and Tobias Ritter* \\ Department of Chemistry and Chemical Biology, Harvard University, 12 Oxford Street, Cambridge, MA \\ RECEIVED DATE; ritter@chemistry.harvard.edu
}

Functionalized aryl fluorides are used as pharmaceuticals and agrochemicals, in part due to their favorable pharmacological properties such as increased metabolic stability. ${ }^{1}$ Aryl fluorides also find applications as tracers in positron emission tomography (PET) using the $\left[{ }^{18} \mathrm{~F}\right]$ isotope. ${ }^{2}$ Carbon-fluorine bond formation is challenging when compared to other carbon-heteroatom bond formations. ${ }^{3}$ Electrophilic and nucleophilic fluorination as well as the pyrolysis of diazonium tetrafluoroborates are established reactions for the synthesis of fluoroarenes. ${ }^{4}$ Such conventional fluorination reactions, however, exhibit narrow substrate scope with respect to the electronic structure of the arene and the functional groups present, and are therefore typically not applicable to late-stage introduction of fluorine into functionalized molecules. In this communication we present a practical fluorination reaction of functionalized aryl stannanes mediated by $\operatorname{Ag}(\mathrm{I})$. The reaction is general with respect to substrate scope, practical because it can be performed using commercially available reagents, and applicable to the late-stage fluorination of complex molecules such as quinine. The functional group tolerance reported herein has not been demonstrated for any other arene fluorination reaction. The presented fluorination reaction may therefore be applicable to the development of new fluorinated pharmaceuticals.

The electrophilic fluorination of aryl lithium or aryl Grignard reagents can afford aryl fluorides. ${ }^{5}$ For example, fluorination of phenylmagnesium bromide affords fluorobenzene in $61 \%$ yield, fluorination of 1-naphthylmagnesium bromide affords 1fluoronaphthalene in $17 \%$ yield, and fluorination of 1naphthyllithium affords 1-fluoronaphthalene in $72 \%$ yield. $^{6}$ However, in addition to the high basicity of group 1 and 2 organometallics, which limits their functional group tolerance, the yield of fluorination can vary. ${ }^{6}$ Likewise, no general fluorination reaction of aryl stannanes, aryl zinc reagents, arylboronic acid derivatives, or any other aromatic main group organometallic has previously been described. ${ }^{7}$ While electrophilic fluorination of main group organometallics proceeds via direct fluorination of the metal-carbon $\sigma$-bond, we have shown that aryl palladium complexes can be oxidized at palladium to afford high-valent palladium fluoride complexes that subsequently yield carbonfluorine bond formation through reductive elimination. ${ }^{8}$ Guided by the hypothesis that transition metals can yield aryl fluorides more efficiently than main group organometallics due to redox participation of the metal and subsequent carbon-fluorine reductive elimination from a high-valent metal fluoride, we identified $\operatorname{Ag}(\mathrm{I})$ as a transition metal to mediate fluorination.

We observed that treatment of (4-biphenyl)tributylstannane with 2.0 equiv of AgOTf and 1.2 equiv of F-TEDA-BF (1) in $_{4}$ acetone at $23{ }^{\circ} \mathrm{C}$ afforded the aryl fluoride in $70 \%$ isolated yield within 20 minutes (eq 1). The use of AgOTf as $\operatorname{Ag}(\mathrm{I})$ source afforded the highest fluorination yields with acetone being the optimal solvent (for fluorination reactions using other $\mathrm{Ag}(\mathrm{I})$ salts, see Supporting Information). When the fluorinating reagent F-
TEDA-PF 6 (2) was used instead of $\mathbf{1}$, the yield of fluorination increased to $83 \%$. The increased yield may be due to arylation of the tetrafluoroborate anion of $\mathbf{1}$ by the aryl stannane to afford aryl borates. ${ }^{9}$ The hexafluorophosphate counterion in $\mathbf{2}$ is less likely to participate in transmetallation. The silver-mediated fluorination is operationally simple, scalable, proceeds within 20 minutes at room temperature, affords fluorinated arenes in 63$83 \%$ yield, and tolerates electron-poor, electron-rich, ortho,orthodisubstituted arenes, as well as heteroaromatics (Table 1).

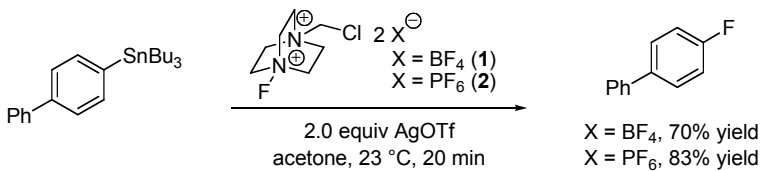

$\operatorname{Ag}(\mathrm{I})^{10}$ has been used to accelerate the fluorination of vinyl stannanes with electrophilic fluorination reagents. ${ }^{11}$ Vinyl stannanes can react with $\mathbf{1}$ in the absence of silver, ${ }^{12}$ but the reaction rate can be increased using $\operatorname{Ag}(\mathrm{I})$ salts. ${ }^{1 \mathrm{cc}}$ In contrast to vinyl stannanes, electron-neutral aryl stannanes do not react with 1 to form aryl fluorides. In the absence of $\mathrm{Ag}(\mathrm{I})$, the reaction shown in eq 1 afforded no fluorination product after $24 \mathrm{~h}$ at $23^{\circ} \mathrm{C}$. The fluorination of aryl stannanes can proceed with strong fluorinating reagents such as elemental fluorine and acetylhypofluoride, which allow for the fluorination of simple molecules such as fluorobenzene. ${ }^{13}$

Table 1. Electrophilic fluorination of aryl stannanes. ${ }^{a}$

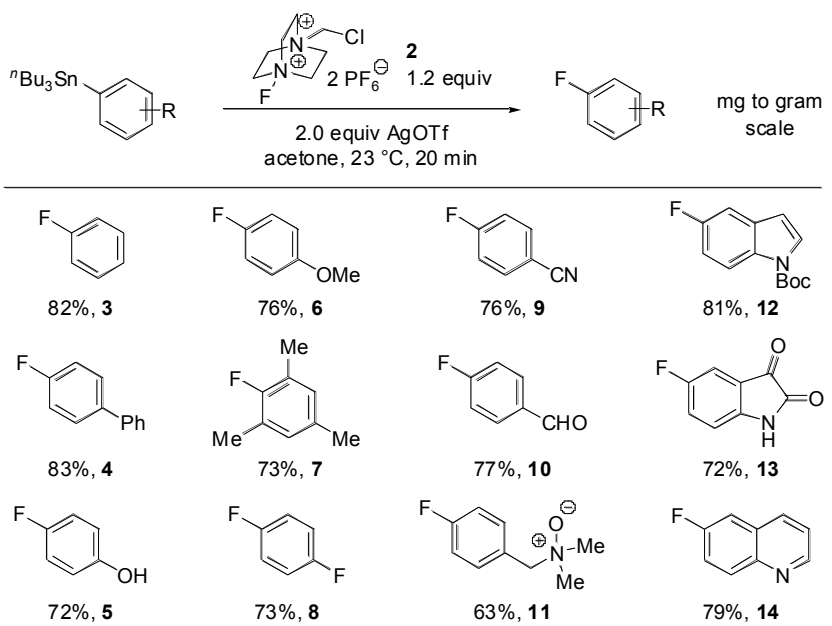

a) Aryl trimethylstannanes can be used instead of aryl tributylstannanes.

Subsequent to the synthesis of the simple fluoroarenes shown in Table 1, we evaluated late-stage fluorination of biomedically active aromatics (Scheme 1). Introduction of the stannyl functionality can be accomplished in one step from aryl iodides or bromides, or in two steps from the corresponding phenols by palladium-catalyzed stannylation of triflates ${ }^{14}$ as shown for estrone in Scheme 1. Stannylation proceeded in the presence of a 
variety of functional groups and delivered stable organometallics that typically were purified by chromatography on silica gel. Fluorination of stannyl estrone under identical reaction conditions as described in Table 1 afforded 3-fluoro-3-deoxyestrone (15) in $85 \%$ yield. The three step procedure-triflation, stannylation, fluorination - from readily available phenols was extended to the synthesis of fluoro derivatives of $\delta$-tocopherol, camptothecin, and quinine. The presented fluorination reaction allows late-stage fluorination of highly functionalized molecules.

Scheme 1. Fluorination of pharmaceutically active molecules.
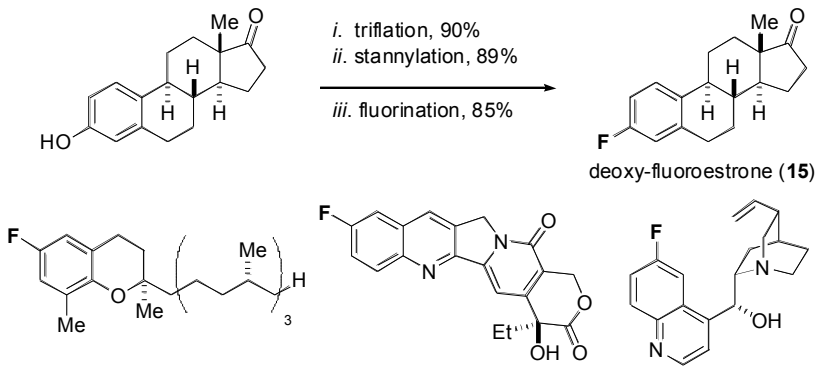

deoxy-fluoro- $\delta$-tocopherol (16), 69\% yield fluorocamptothecin (17), $70 \%$ yield

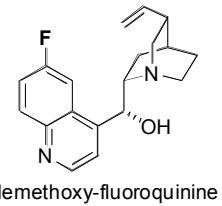

(18), $73 \%$ yield i. $\mathrm{Tf}_{2} \mathrm{O}, \mathrm{NEt}_{3} ;$ ii. $\mathrm{LiCl}, 5 \mathrm{~mol} \% \mathrm{Pd}\left(\mathrm{PPh}_{3}\right)_{4},\left({ }^{n} \mathrm{Bu}_{3} \mathrm{Sn}\right)_{2} ;$ iii. conditions, see Table 1. Yields for 16, 17, and $\mathbf{1 8}$ given for fluorination.

Present challenges to fluorination include the use of aryl stannanes, which, despite functional group tolerance and synthetic utility, are toxic. While the yields of fluorination are uniformly high (63-85\%) using identical reaction conditions for all substrates, we observed 10-20\% of hydrodestannylated products in addition to the desired fluorination product, which can make purification on gram scale challenging.

Preliminary mechanistic investigations suggest that fluorination may occur from a redox active aryl silver species with the participation of more than one silver atom per carbon-fluorine bond formation event. Upon addition of two equiv of AgOTf to tributyl(4-fluorophenyl)stannane in $\mathrm{Et}_{2} \mathrm{O}$, the transmetallation product $\left(4-\mathrm{F}-\mathrm{C}_{6} \mathrm{H}_{4} \mathrm{Ag}\right)_{5} \quad(\mathrm{AgOTf})_{2}(\mathbf{1 9})$ was isolated (Scheme 2$) .{ }^{15}$ Fluorination of $\mathbf{1 9}$ with $\mathbf{2}$ afforded 1,4-difluorobenzene in $45 \%$ yield. Addition of 0.6 equiv AgOTf to $\mathbf{1 9}$ followed by $\mathbf{2}$ afforded 1,4-difluorobenzene in $83 \%$ yield. The postulated intermediate (ArAg) (AgOTf) complex 20 was observed by ${ }^{1} \mathrm{H}$ and ${ }^{19} \mathrm{~F}$ NMR but not isolated. Purified 4-fluorophenylsilver reacted with 2 to give 1,4-difluorobenzene in $47 \%$ yield, ${ }^{16}$ and 1.0 equiv of additional AgOTf was required to obtain a fluorination yield of $84 \%$. In situ fluorination (eq 1) proceeded with one equiv of AgOTf (68\% yield) and with $10 \mathrm{~mol} \%$ (36\% yield, 3.6 turnovers). Catalysis using $10 \mathrm{~mol} \%$ of AgOTf and two equivalents of NaOTf with slow addition of arylstannane increased the yield from $36 \%$ to $53 \% .{ }^{17}$ However, two equiv of AgOTf are required to obtain the yields reported in Table 1. A 1:1 ratio of ArAg to AgOTf is required for optimal yields. Additional AgOTf beyond a 1:1 ratio did not improve the yield of fluorination.

Scheme 2. 1:1 ratio ArAg:AgOTf required for high fluorination yield.

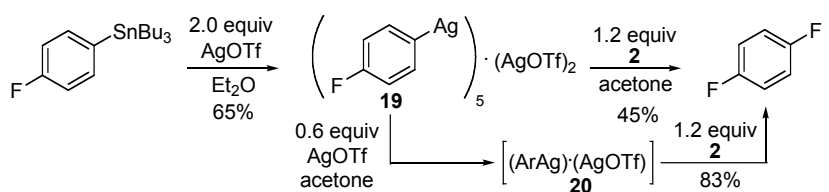

Based on our results, we hypothesize that the silver-mediated carbon-fluorine bond formation involves bimetallic oxidationreductive elimination (Scheme 3). Reductive elimination, a two electron process, could proceed via one-electron redox participation of two silver atoms. While we did not observe highvalent aryl silver fluoride intermediates, the addition of BHT or galvinoxyl free radical as radical scavengers did not influence the yield of fluorinated products, suggesting that the formation of free radical intermediates is unlikely.

Scheme 3. Proposed bimetallic oxidation-reductive elimination.

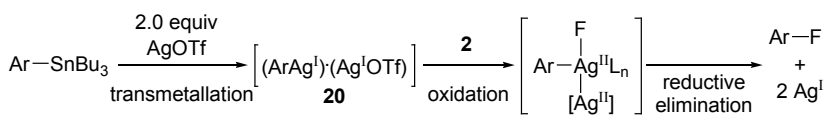

In conclusion, we report a regiospecific silver-mediated fluorination of aryl stannanes. Advantages of the fluorination reaction include the ease of starting material preparation, even for complex substrates, its operational simplicity using readily available reagents such as AgOTf, and the applicability to a broader substrate scope than has been demonstrated for any other arene fluorination reaction. Conceptually, silver-mediated oxidative transformations of aryl nucleophiles that proceed via bimetallic redox processes are a new avenue for carbonheteroatom bond formations.

Acknowledgement. We thank Merck and Amgen for unrestricted support and Eli Lilly for a graduate fellowship for TF.

Supporting Information Available: Detailed experimental procedures and spectroscopic data for all new compounds. This material is available free of charge via the Internet at http://pubs.acs.org.

REFERENCES

(1) a) Müller, K.; Faeh, C.; Diederich, F. Science 2007, 317, 1881-1886; b) Kirk, K. L. Org. Process Res. Dev. 2008, 12, 305-321; c) Jeschke, P. Chembiochem 2004, 5, 570-589.

(2) Lasne, M. C.; Perrio, C.; Rouden, J.; Barre, L.; Roeda, D.; Dolle, F.; Crouzel, C., Chemistry of beta(+)-emitting compounds based on fluorine18. In Contrast Agents II, 2002; Vol. 222, pp 201-258.

(3) a) Chambers, R. D., Fluorine in organic chemistry. Oxford: New York, 2004; b) Furuya, T.; Kuttruff, C. A.; Ritter, T. Curr. Opin. Drug. Disc. Dev. 2008, 11,803-819.

(4) a) Sandford, G. J. Fluorine Chem. 2007, 128, 90-104; b) Adams, D. J.; Clark, J. H. Chem. Soc. Rev. 1999, 28, 225-231; c) Balz, G.; Schiemann, G. Ber. Deutsch. Chem. Ges. 1927, 60, 1186-1190.

(5) a) Davis, F. A.; Han, W.; Murphy, C. K. J. Org. Chem. 1995, 60, 4730 4737; a review: b) Baudoux, X ; Cahard Org. React. 2007, 69, 347-672.

(6) a) Lal, G. S. J. Org. Chem. 1993, 58, 2791-2796; b) Differding, E.; Wehrli, M. Tetrahedron Lett. 1991, 32, 3819-3822.

(7) Furuya, T.; Kaiser, H. M.; Ritter, T. Angew. Chem., Int. Ed. 2008, 47 5993-5996.

(8) a) Furuya, T.; Ritter, T. J. Am. Chem. Soc. 2008, 130, 10060-10061. For fluorinations that may also proceed via high-valent palladium intermediates, see: b) Hull, K. L.; Anani, W. Q.; Sanford, M. S. J. Am Chem. Soc. 2006, 128, 7134-7135; c) Kaspi, A. W.; Yahav-Levi, A.; Goldberg, I.; Vigalok, A. Inorg. Chem. 2008, 47, 5-7.

(9) Hofstee, H. K.; Boersma, J.; van der Kerk, G. J. M. J. Organomet. Chem. 1979, 168, 241-249.

(10) For the use of $\operatorname{Ag}(\mathrm{I})$ in organic synthesis, see: a) Naodovic, M.; Yamamoto, H. Chem. Rev. 2008, 108, 3132-3148; b) Weibel, J. M. Blanc, A.; Pale, P. Chem. Rev. 2008, 108, 3149-3173; c) Alvarez-Corral, M.; Munoz-Dorado, M.; Rodirguez-Garcia, I. Chem. Rev. 2008, 108, 3174-3198; d) Yamamoto, Y. Chem. Rev. 2008, 108, 3199-3222; e) Li, Z. G.; He, C. Eur. J. Org. Chem. 2006, 4313-4322.

(11) a) Tius, M. A.; Kawakami, J. K. Synth. Commun. 1992, 22, 1461-1471; b) Tius, M. A.; Kawakami, J. K. Synlett 1993, 207-208; c) Tius, M. A.; Kawakami, J. K. Tetrahedron 1995, 51, 3997-4010.

(12) Matthews, D. P.; Miller, S. C.; Jarvi, E. T.; Sabol, J. S.; McCarthy, J. R Tetrahedron Lett. 1993, 34, 3057-3060.

(13) a) Adam, M. J.; Pate, B. D.; Ruth, T. J.; Berry, J. M.; Hall, L. D. J. Chem. Soc., Chem. Commun. 1981, 733-733; b) Adam, M. J.; Ruth, T. J.; Jivan, S.; Pate, B. D. J. Fluorine Chem. 1984, 25, 329-337.

(14) a) Azizian, H.; Eaborn, C.; Pidcock, A. J. Organomet. Chem. 1981, 215 49-58; b) Saa, J. M.; Martorell, G.; Garciaraso, A. J. Org. Chem. 1992, 57, 678-685; c) Echavarren, A. M.; Stille, J. K. J. Am. Chem. Soc. 1987, $109,5478-5486$.

(15) a) Krause, E.; Schmitz, M. Ber. Deut. Chem. Ges. 1919, 52, 2150-2164; b) Beverwijk, C. D. M.; van der Kerk, G. J. M. J. Organomet. Chem. 1972, 43, C11-C12.

(16) For polynuclear Ag aryls, see: Meyer, E. M.; Gambarotta, S.; Floriani, C.; Chiesivilla, A.; Guastini, C. Organometallics 1989, 8, 1067-1079.

(17) We thank a reviewer for the suggestion of this experiment. 


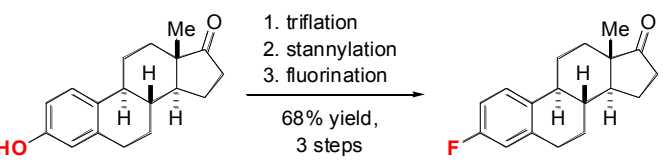

We report a regiospecific silver-mediated fluorination of aryl stannanes. The presented reaction can afford complex fluoroarenes from readily available phenols in three steps. The operational simplicity and the broad substrate scope of the fluorination should render this reaction a useful tool for the synthesis of $\mathrm{mg}$ to gram quantities of functionalized aryl fluorides. Silver-mediated oxidative transformations of aryl nucleophiles that proceed via bimetallic redox processes are a new avenue to develop carbon-heteroatom bond formations. 